\title{
Dialogia
}

\section{O direito humano à educação e o homeschooling no Brasil: análise constitucional da compatibilidade com o mínimo existencial à educação}

\author{
The human right to education and homeschooling in brazil: \\ constitutional analysis of compatibility with the existential minimum of \\ education
}

Maristela Denise Marques de Souza Pontifícia Universidade Católica do Paraná maristela.marques@pucpr.br

Miriam Olivia Knopik Ferraz Pontifícia Universidade Católica do Paraná Universidade Positivo FAE Centro Universitário. m.okf@hotmail.com

Ariê Scherreier Ferneda Pontifícia Universidade Católica do Paraná. ariefernedaxx@gmail.com

Resumo: Objetiva-se avaliar se a modalidade educacional de homeschooling no Brasil se compatibiliza com o mínimo existencial à educação, enquanto Direito Humano Fundamental. Utiliza-se da metodologia lógico-dedutiva, realizando a análise comparada com o texto constitucional e suas disposições sobre a educação e o homeschooling. O estudo é divido em dois tópicos: aborda-se o direito humano e fundamental à educação com o enfoque na composição do mínimo existencial; aborda-se o homeschooling no Brasil e sua compatibilidade com o mínimo existencial, traçando-se críticas e construções a partir do RE 888.815/RS. Atualmente não é possível a utilização da modalidade, vez que não há legislação correspondente que proporcione um sistema de garantia do cumprimento dos requisitos mínimos, e assim assegurar a efetivação do mínimo existencial à educação.

Palavras-chave: Homeschooling. Educação Domiciliar. Educação. Mínimo Existencial.

Abstract: The objective is to evaluate whether the educational modality of homeschooling in Brazil is compatible with the existential minimum to education, as a fundamental human right. It uses the logical-deductive methodology, performing the analysis compared with the constitutional text and its provisions on education and homeschooling. The study is divided into two topics: the human and fundamental right to education is addressed with a focus on the composition of the existential minimum; addressing homeschooling in Brazil and its compatibility with the existential minimum, tracing criticisms and constructions from RE $888.815 / \mathrm{RS}$. It is not possible to use the modality, since there is no corresponding legislation that provides a system to guarantee compliance with the minimum requirements, and thus ensure the implementation of the existential minimum to education.

Keywords: Homeschooling. Home Education. Education. Existential Minimum. 


\section{Introdução}

Há vários motivos como divergências metodológicas, crenças e culturas que podem ensejar a opção pelo modelo de educação domiciliar (bomeschooling). A educação é um direito fundamental social, o qual é desenvolvido com atenção ao pluralismo e ao pleno desenvolvimento e, ainda, deve ser garantido pelo Estado em observância ao mínimo existencial para que se torne possível o alcance de uma vida digna. Como compatibilizar o homeschooling com o mínimo existencial à educação? Para a resolução dessa questão, o artigo divide-se em dois momentos de análise: a análise do direito humano e fundamental à educação e a composição do mínimo existencial; e, em um segundo momento a compreensão do homeschooling e de sua compatibilidade constitucional com o mínimo existencial.

\section{$1 \mathrm{O}$ direito humano e fundamental à educação: a composição do mínimo existencial}

A educação é um direito fundamental previsto constitucionalmente e está intimamente relacionado à dignidade da pessoa humana e ao próprio exercício da cidadania, constitui dever da família, do Estado e da sociedade. Neste tópico pretende-se (i) compreender como este direito é abrangido em nível constitucional; e (ii) como ele pode ser efetivado, transpassando-se pelo mínimo existencial e os sujeitos competentes.

Nesse sentido, considerando tratar-se de um direito social, a educação, enquanto direito humano e fundamental, encontra-se previsto no artigo $6^{\circ}$ da Constituição da República Federativa do Brasil (CRFB) ${ }^{\mathrm{i}}$. Ingo Wolfgang Sarlet analisa o posicionamento do dispositivo apontando a inovação na topografia constitucional: se verifica a partir da posição em que os direitos e garantias fundamentais ocuparam junto à CRFB, logo após o preâmbulo e os princípios fundamentais (arts. $1^{\mathrm{o}}$ ao $4^{\circ}$ ). A inserção dos direitos fundamentais sociais em capítulo próprio, situado no catálogo dos direitos fundamentais, ressalta, de forma incontestável, essa sua condição (SARLET, 2015, p. $57)$.

Para além de sua previsão no rol de direitos e garantias fundamentais, o constituinte aprofundou a regulamentação da educação junto ao Título VIII - "Da Ordem Social", especificamente nos art. 205 ao art. 214, tratando de questões como objetivos, princípios, garantias, condições, conteúdos mínimos, organização estatal e a vinculação de receitas tributárias. Para Sarlet, essas disposições refletem essencialmente o âmago do Direito fundamental social à educação, considerando que apresentam a fundamentalidade formal e, também material do referido 
direito. Isto é, a fundamentalidade formal refere-se ao direito constitucional positivo; enquanto a fundamentalidade material decorre da "circunstância de serem os direitos fundamentais elemento constitutivo da Constituição material”. (SARLET, 2015, p. 348). A partir da leitura do art. 205 da CRFB percebe-se que a educação é um direito de todos e dever do Estado e da família. Esse direito deve ser promovido e incentivado com a colaboração da sociedade, com vista ao pleno desenvolvimento da pessoa, seu preparo para o exercício da cidadania e sua qualificação para o trabalho.

Para a materialização deste direito há a necessidade da atuação do Poder Público por meio da organização de sistemas educacionais públicos e que garantam, no mínimo, os serviços indicados no art. 208 da CRFB. Há a necessidade de que a União, os Estados, o Distrito Federal e os Municípios em regime de colaboração destinem orçamentos e recursos específicos em conformidade com os mínimos apontados no art. 212 da CRFB (SILVA, 2005, p. 784).

O art. 206 elenca um rol de princípios constitucionais do ensino, dos quais se destacam (i) a igualdade de condições para o acesso e permanência na escola (inciso I), como princípio derivativo da isonomia; (ii) a gratuidade do ensino público em estabelecimentos oficiais (inciso IV) e que esteve presente em todas as Constituições do Brasil, exceto pela Constituição de 1891; e (iii) a garantia de padrão de qualidade (inciso VII).

Segundo Marcos Augusto Maliska, referente ao primeiro (i) princípio (2013, p. 116), o acesso e a permanência na escola devem ser vistos sob a perspectiva das diferenças, levando em conta o direito ao pluralismo sem, no entanto, desprestigiar o tratamento isonômico. Isso se verifica, por exemplo, no acesso adequado de pessoas com deficiência física à educação, considerando todas as suas peculiaridades e necessidades, bem como na inclusão do indígena à rede de educação levando em conta o seu direito de manutenção de sua cultura própria. Frente ao segundo (ii) princípio, ressalta-se que a CRFB o garante expressamente como direito público subjetivo no $₫ 1^{\circ}$ do art. $208^{\text {ii }}$, bem como nos incisos I e II do próprio artigo em comento. Apontase, ainda, que não há outro direito fundamental que tenha recebido tal distinção no texto constitucional.

Esta condição municia, por si só, a exigência de cumprimento do que se estabelece com o direito à educação em relação à gratuidade da sua prestação nos termos propostos pelo constituinte. Caso a prestação seja deficiente, a Lei Fundamental estabelece que "o não oferecimento do ensino obrigatório pelo Poder Público, ou sua oferta irregular, importa responsabilidade da autoridade competente", nos termos do art. 208, $₫ 2^{\circ}$ da CRFB. 
Em relação ao terceiro (iii) princípio, Rodrigo Albuquerque de Victor (2011, p. 84) aponta que "não é pelo número de creches e escolas construídas que se mede a educação de um povo", mas também pelo papel fundamental que exercem o transporte escolar, a merenda e programas de assistência social.

Nada obstante, o texto constitucional é rico em referências à qualidade como objetivo educacional, sujeitando o ensino oriundo de iniciativa privada aos parâmetros de qualidade estabelecidos pelo Poder Público (art. 209, II, CRFB), bem como quando distribui competência à União para organizar um sistema federal de ensino, de forma a garantir um "padrão mínimo de qualidade" (art. 211, $\left.₫ 1^{\circ}, \mathrm{CRFB}\right)$.

Por fim, o constituinte exige que a distribuição de recursos para financiar a educação, por parte da União, deve assegurar, inclusive, a garantia de padrão de qualidade e equidade (art. 212, \$3 $3^{\circ}, \mathrm{CRFB}$ ) e que o Plano Nacional de Educação - PNE, a ser estabelecido em lei, deverá articular o sistema nacional de educação com vista a conduzi-lo para melhoria da qualidade de ensino (art. 214, III, CRFB), dentre outros objetivos.

Sendo assim "a educação de qualidade, em todos os níveis e modalidades, para todos, é um direito humano essencial" (CAMBI; ZANINELLI, 2014, p. 29). Nesse sentido, se há direito público subjetivo à educação, o Estado pode e tem de entregar a prestação educacional. Considerando a exigência de atuação estatal para sua concreção, passa-se, por oportuno, à análise do mínimo existencial à educação, enquanto um conjunto de prestações materiais que são indispensáveis a uma vida condigna (SARLET; ZOCKUN, 2016, p. 127).

O mínimo existencial, segundo Ingo Wolfgang Sarlet, pode ser em sua essência aproximada da garantia de um mínimo necessário está ligada a proteção da dignidade humana (SARLET, 2013, p. 20), em observância as bases de um Estado Social e do direito à vida (NOVAIS, 2010, p. 80-81). Quanto ao conteúdo do mínimo existencial, aponta-se a existência de um "direito ao mínimo existencial" (SCHIER; SCHIER, 2016, p. 215) que estaria relacionado a prestações básicas vinculadas a ideia do viver dignamente (SARLET; FIGUEIREDO, 2010, p. 24) e, por isso, integrariam o próprio conceito de direitos fundamentais (TORRES, 2009, p. 314).

Para a sua concretude é necessário compreendê-lo como um conjunto de deveres do poder público (CLÈVE; FREIRE, 2003, p. 27) e, por isso, é composto por atendimento básico e eficiente de saúde, acesso a alimentação básica e vestimentas, educação de primeiro grau e a moradia, mas que a materialização específica de cada um depende da realidade de cada país (KRELL, 2002, p. 63), ou ainda, a composição desse mínimo é componente de um núcleo irredutível do "princípio 
da dignidade humana" relacionado aos direitos de liberdade e a limita a quatro ordens prestacionais: educação fundamental, saúde básica, assistência aos desamparados e ao acesso ao judiciário (BARCELLOS, 2011, p. 288-289). Apesar de a doutrina majoritária vincular o mínimo existencial ao princípio da dignidade humana (TORRES, 2009, p. 35; BARCELLOS, 2011, p. 288-289; SILVA, 2000, p.92; SARLET, 2012, p. 85; HACHEM, 2013, p. 98), resta dúvida sobre qual seria a "linha abaixo da qual não há dignidade" (HACHEM, 2013, p. 98), em que a violação ensejaria o desrespeito a esse princípio.

Essa garantia não está limitada apenas a sobrevivência física, mas deve abranger prestações que facilitem e desenvolvam a própria existência dos indivíduos, o gozo de direitos e o livre desenvolvimento da personalidade. (HACHEM, 2013, p. 98) Segundo Daniel Wunder Hachem há duas correntes doutrinárias que trazem diferentes compreensões sobre o mínimo existencial: (i) o mínimo existencial definitivo (TORRES, 2009, p. 84,87-89; BARCELLOS, 2011, p. 243; BITTENCOURT NETO, 2010, p. 130-131; HONÓRIO, 2009, p. 58-61; HACHEM, 2013, p. 119) e o (ii) mínimo existencial prima facie. iii

A primeira (i) aplica a regra do tudo-ou-nada de Dworkin (2010, p. 39), ou seja, o mínimo deve ser materializado em termos absolutos, não sendo possível um sopesamento, vez que este já teria sido feito pelo constituinte. (HACHEM, 2013, p. 115-116). Assim, o mínimo existencial seria um critério de justiciabilidade utilizado para verificar a extensão da legitimidade do Poder Judiciário para a efetivação dos direitos sociais. Dentro desses parâmetros seria possível a concessão pelo judiciário, sem que fosse possível a invocação da ideia da reserva do possível. (TORRES, 2009, p. $53,54$ e 105,106$)$.

A segunda (ii) adota o entendimento do mínimo existencial na categoria de princípios jurídicos (ALEXY, 2014, p. 67-71), ou seja, seriam aplicáveis "na máxima medida possível" (HACHEM, 2013, p. 118) observando cada caso na prática. Salienta-se que essa teoria está submetida às regras de ponderação e, assim, haveria a possibilidade do prevalecimento de outros pontos em detrimento ao mínimo existencial, como a separação de poderes, o princípio democrático, a reserva legal orçamentária, entre outros. (SARLET; FIGUEIREDO, 2010, p. 321, 322 e 350-351). Por essa razão, é possível observar uma insegurança jurídica no fortalecimento e proteção ao mínimo existencial e, por isso, esse trabalho coaduna-se com a primeira teoria quanto à visão do mínimo existencial como definitivo, evitando-se que para cada caso haja um mínimo. (HACHEM, 2013, p. 119-121)

Todavia, insurge a dúvida: como determinar um conteúdo do mínimo existencial diante de tantas distinções? A doutrina atual elenca duas possibilidades de fixação de seu conteúdo: (i) o 
conteúdo do mínimo seria determinável no caso concreto, ou seja, não seria possível estipular o mínimo a priori, mas somente após a análise das particularidades de cada caso concreto; e (ii) a determinação do conteúdo seria possível por meio da fixação de um rol constitucional preferencial, a priori, que pudesse proteger e abarcar as principais situações. (HACHEM, 2013, p. 118-121)

Depositar a formulação do mínimo somente ao caso concreto e sob a possibilidade de cada magistrado o definir, com base em suas convicções, possibilitaria que inúmeros entendimentos fossem formulados e, ao fim, ninguém soubesse do que se trataria em específico o instituto e a sua exigibilidade judicial estaria fadada ao fracasso (HACHEM, 2013, p. 121; BITTENCOURT NETO, 2010, p. 131).

Adota-se a posição da necessária composição do conteúdo do mínimo existencial por meio de um rol a priori através do estudo da normativa constitucional em sua completude. Assim, com base na doutrina colidada, ainda que de forma não definitiva, busca-se definir o conteúdo do mínimo existencial à educação, para que sirva de base e fundamento para a formulação de escolhas políticas, no sentido de se autorizar ou não a prática do homeschooling.

Assim, o mínimo existencial referente ao direito à educação pertence à noção de "rol constitucional preferencial", como aponta Daniel Hachem. Ou seja, uma prioridade imposta por normas constitucionais, por exemplo, que faz com que determinadas escolhas políticas-jurídicas correspondam a uma ordem de prioridades referentes a cada Estado em seus momentos históricopolítico (HACHEM, 2014, p. 95).

A construção dogmática dos contornos do mínimo existencial foi realizada por Ana Paula de Barcellos e possui uma tradução direta dos dispositivos constitucionais, apontando um rol preferencial e não absoluto (BARCELLOS, 2011, p. 300-302). Com base na Constituição a autora separa as que fazem parte do mínimo existencial em quatro grupos: a educação básica, a saúde básica, a assistência aos desamparados e o acesso à Justiça. Para Barcellos (2011, p. 302-305), o mínimo existencial engloba apenas as prestações sobre a "educação básica", que é disposta na Constituição como obrigatória e gratuita (art. 208, I da CRFB/88). Efetivamente, a materialização dessa “educação básica” está determinada no art. 21, I da Lei de Diretrizes e Bases da Educação (Lei n. 9.394/1996), e, portanto, engloba a educação infantil, o ensino fundamental e o ensino médio. Para se compreender as limitações dessa imposição, a educação superior estaria fora da proteção do mínimo existencial, mas não deixa de ser parte do direito fundamental social à educação (HACHEM, 2014, p. 96).

Como aponta Daniel Hachem (2014, p. 96), o mínimo existencial que está sendo tratado não se refere às "condições ideais do desenvolvimento humano, mas sim das condições para uma 
vida minimamente digna, que não requerem necessariamente altos níveis de escolaridade, embora seja desejável o seu alcance progressivo". A grande importância dessa noção é que o indivíduo poderá judicializar requerendo a materialização deste direito, vez que constitui, segundo o $\$ 1^{\circ}$ do art. 208 da CRFB, “direito público subjetivo” e, assim, o não oferecimento pelo Poder Público “importa responsabilidade da autoridade competente" (art. 208, $\$ 2^{\circ}, \mathrm{CRFB}$ ).

No mesmo sentido, há a possibilidade da atuação da iniciativa privada, entretanto, esta não está condicionada somente as regras do livre mercado, devendo cumprir as normas gerais da educação nacional, atuar mediante autorização e avaliação de qualidade periódica e deve possuir capacidade de autofinanciamento, como se observa do art. $7^{\circ}$ da Lei n. 9394/1996.

Dessa forma, compreende-se que o mínimo existencial busca eximir as condições de miséria absoluta, inclusive educacionais, enquanto os direitos econômicos e sociais estão relacionados à promoção da igualdade entre os indivíduos (TORRES, 2009, p. 14-17), a qual deve ocorrer de forma progressiva.

2 O Homeschooling no Brasil e sua compatibilidade com o mínimo existencial: críticas e construções a partir do RE 888.815/RS

A educação domiciliar pode ser entendida como uma modalidade de ensino na qual os pais ou responsáveis conduzem a educação de crianças e adolescentes, tanto em sua formação moral, quanto intelectual (XAVIER, 2019, p. 17).

A educação trata-se de um encontro de pessoas que buscam a "razão de ser dos acontecimentos" (FREIRE, 1977, p. 77), de forma a estimular a reflexão sobre a realidade e o pensamento crítico. Como visto, a educação é um direito fundamental, sendo promovida e incentivada por toda a sociedade e por meio do dever de solidariedade entre família e Estado, com o fim de promover o pleno desenvolvimento da pessoa..$^{\text {iv }}$ Nada obstante, "exercer o direito à educação é essencial para desenvolver a personalidade e implementar os outros direitos humanos, pois dela ninguém poderá ser excluído”. (BRASIL, Ministério da Educação, 2018). Sendo assim, o direito à educação consiste em um direito de aprender ao longo da vida e tem como fundamento os princípios de obrigatoriedade e gratuidade e o direito a não discriminação (BRASIL, Ministério da Educação, 2018).

A Lei de Diretrizes e Bases da Educação prevê, em seu art. $1^{\circ}$, que a educação, a qual se desenvolve por meio do ensino em instituições próprias, abrange os processos de formação que se apresentam na vida familiar, na convivência humana, no trabalho, nas instituições de ensino e pesquisa, nos movimentos sociais e organizações da sociedade civil e nas manifestações culturais. 
Sendo dever da família e do Estado, a educação deve ser inspirada pelos princípios de liberdade e nos ideais de solidariedade humana, nos termos do art. $2^{\circ}$ da referida Lei.

É obrigação dos pais ou responsáveis matricular seus filhos ou pupilos na rede de ensino. ${ }^{\mathrm{N}}$ Há aqueles que resistem ao ensino regular sob o argumento de que a inserção da criança em turmas multiseriadas, por exemplo, pode causar diversos problemas e malefícios, como o convívio com alunos mais velhos e com sexualidade mais avançada e a existência, na rede de ensino, de hábitos e culturas distintas.

Aludidos argumentos foram utilizados em um Mandado de Segurança interposto por V. $\mathrm{D}^{1}$., representada por seus genitores, em que pleitearam o direito líquido e certo à educação domiciliar em razão de sua insatisfação com os parâmetros educacionais e discordância de algumas imposições pedagógicas do ensino regular (RIO GRANDE DO SUL, 2013).

Em primeira instância, o magistrado negou provimento ao pedido sob a justificativa de que o convívio em sociedade implica o respeito pelo que é diferente. Isto é, “o mundo não é feito de iguais". Salienta que a escola é um ambiente de socialização essencial para a formação dos indivíduos, bem como o desenvolvimento da alteridade necessária ao convívio em sociedade (RIO GRANDE DO SUL, 2013).

Assim, diante da insatisfação com a sentença, foi interposta Apelação Cível n. 70052218047, oportunidade em que o desembargador relator, Ricardo Pastl, apontou a previsão constitucional referente à liberdade de aprender, ensinar, pesquisar e divulgar o pensamento, a arte e o saber, nos termos do art. 205, II, da CRFB. Essa liberdade "não significa a permissão aos pais de restringir indevidamente o direito social fundamental à educação", conforme o art. 6, caput, da CRFB (RIO GRANDE DO SUL, 2013). Ao indeferir o pedido, entendeu que "o ensino é obrigatório e a frequência na escola é indispensável, não existindo previsão legal ou constitucional de ensino na modalidade domiciliar” (RIO GRANDE DO SUL, 2013).

A matéria, então, foi levada ao Supremo Tribunal Federal. Reconhecida a repercussão geral do Recurso Extraordinário n. 888.815, o relator, Ministro Roberto Barroso, fez os seguintes questionamentos: "têm os pais o direito à opção de, em lugar de matricular os seus filhos numa escola oficial, educá-los formalmente em casa?” e qual o regramento deve-se aplicar no interesse da criança? (BRASIL, STF, 2018). O Plenário do STF, por sua vez, negou provimento ao Recurso Extraordinário $^{\text {vi }}$, e considerou constitucional a prática de homeschooling em razão da sua compatibilidade com as finalidades e os valores da educação infanto-juvenil previstos na CRFB.

${ }^{1}$ Com o objetivo de preservar a identidade da criança, não será divulgado o seu nome completo. 
(BRASIL, STF. Notícias, 2018). A maioria votou pelo desprovimento do RE, uma vez não há regulamentação, no que tange à execução e fiscalização, para a prática de ensino domiciliar. ${ }^{\text {vii }}$ Isto é, o homeschooling somente passará a existir a partir de uma lei que o discipline.

Em seu voto o relator propôs algumas regras de regulamentação da matéria, com base em limites constitucionais. A proposta prevê a observância dos seguintes requisitos: a) os pais devem notificar às secretarias de educação a sua preferência pelo ensino domiciliar, mantendo um cadastro e registro das famílias que o optaram; b) os educandos devem ser submetidos aos mesmos critérios de avaliação periódica a que se submetem os demais alunos das redes públicas ou privadas; c) as secretarias de educação devem indicar a instituição de ensino onde o educando irá realizar suas avaliações; e d) as secretarias de educação podem compartilhar as informações cadastrais com as demais autoridades públicas, com o fim de que seja possível a fiscalização (BRASIL, STF, 2018). Há ainda propostas que apontam a possibilidade da utilização do Direito Comparado para a solução dessa controvérsia (BARBOZA; KNIHS, 2017, p. 402).

Seguindo as orientações indicadas na ocasião do julgamento do RE $\mathrm{n}^{\circ} .888 .815$, o Projeto de Lei 2401/2019 (BRASIL, Câmara dos Deputados, 2019) estabelece parâmetros para que uma criança ou adolescente possa ser submetido ao ensino domiciliar. O Projeto prevê que a opção domiciliar deverá ser efetuada pelos pais ou responsáveis através de uma plataforma virtual do Ministério da Educação, na qual deverá constar uma série de documentos, incluindo certidões criminais e um plano pedagógico individual (art. $4^{\circ}$, inciso I ao VI). Caberá aos pais ou responsáveis, durante o processo de ensino e de aprendizagem, monitorar o desenvolvimento do estudante, conforme as diretrizes nacionais curriculares (art. 10). O estudante matriculado em regime de educação domiciliar deverá ser submetido, para fins de certificação da aprendizagem, a uma avaliação anual sob a gestão do Ministério da Educação (art. $6^{\circ}$ ).

Para além dos argumentos elencados, necessária se faz uma análise do bomeschooling a partir da perspectiva dos direitos fundamentais sociais e de seu núcleo essencial, o mínimo existencial. A composição do mínimo existencial referente a educação é pautada nos parâmetros: (i) garantia do ensino básico (educação infantil, fundamental e ensino médio); e (ii) a concretização da educação deve ser sempre de forma progressiva, partindo-se do mínimo necessário que é incumbência Estatal.

Como avaliar se o Homeschooling corresponde aos mínimos necessários para que não haja intervenção estatal e a consideração do abandono intelectual? Não há hoje legislação que regulamente o homeschooling, então, qualquer análise sobre esse assunto deve ser feita sob a luz do 
Direito Humano Fundamental à Educação e os feixes jusfundamentais, ou seja, os seus reflexos na legislação infraconstitucional como a Lei de Diretrizes e Bases da Educação.

Nesse sentido, é possível traçar aproximações: há uma necessária relação de responsabilidade solidária entre o Estado e os pais, sendo inadmissível na ordem existente a atuação independente entre eles. Além disso, é possível observar que a Lei de Diretrizes e Bases da Educação possibilita que o ente privado atue desde que seguidos os parâmetros supracitados (cumprimento de normas gerais, atuação mediante autorização e avaliação de qualidade periódica e capacidade de autofinanciamento). Assim, mesmo o ente privado deve atuar com responsabilidade solidária ao Estado, uma política de autonomia, requer um plano público para sua efetivação. viii $^{\text {}}$

Por analogia, respeitadas as diferenças e particularidades essenciais, é possível afirmar que para que o homeschooling possa ser utilizado como uma modalidade educacional ele deve necessariamente respeitar a atuação solidária e responsável em conjunto com o Estado, cumprindo requisitos como normativas gerais de educação, atuação mediante autorização e capacidade de financiamento. Juridicamente, hoje, não é possível a utilização da modalidade, vez que não há legislação correspondente e assim não há garantia do cumprimento dos requisitos mínimos, não assegura a efetivação do mínimo existencial à educação.

As construções das bases para a efetivação dessa modalidade podem ser feitas com base no Julgado como em analogia às disposições correspondentes às entidades privadas. Se observadas as propostas apresentadas pelo Ministro Barroso e o Projeto de Lei 2401/2019, denota-se que se caminha no mesmo sentido para o fortalecimento da responsabilidade família-Estado.

Considerando eventual prática de educação domiciliar, para que o mínimo existencial seja alcançado e que essa prática seja compatível com os ditames constitucionais, é necessário munir o Estado com ferramentas adequadas que garantam a observância dos princípios (igualdade de condições, gratuidade, qualidade do ensino) bem como que essa modalidade de educação garanta, de fato, o pleno desenvolvimento e prezando, pela tolerância e o pluralismo.

A educação é um direito de todos, entretanto, não se limita apenas a ensinar a ler, a escrever ou a fazer cálculos. (PIAGET, 1974, p. 54). Consiste, inclusive, em promover o desenvolvimento de faculdades mentais, aquisição de conhecimentos e valores necessários ao convívio social real. É nesse sentido que se verifica o mínimo existencial: a educação, independente do local onde é oferecida e enquanto promotora de ideias plurais, proporciona instrumentos através dos quais os indivíduos podem levar uma vida digna. Ademais, garantir uma sociedade pluralista e democrática é o que se alcança por meio da atenção progressiva a da promoção dos direitos fundamentais. 


\section{Considerações finais}

O homeschooling é uma realidade no Brasil (BARBOZA; KNIHS, 2017, p. 400), entretanto, a sua efetivação vem sofrendo diversos obstáculos políticos e sociais. O presente estudo teve por objetivo realizar a análise de um dos obstáculos: a compatibilização dessa modalidade educacional com o mínimo existencial à educação, enquanto núcleo essencial do Direito Humano Fundamental à Educação. Por meio do método lógico-dedutivo realizou-se a comparação entre o postulado do mínimo existencial e o homeschooling, inclusive apresentando propostas de aproximações. O estudo foi dividido em dois tópicos: no primeiro abordou-se o direito humano e fundamental a educação em si, e como ele é compreendido na composição do mínimo existencial. No segundo tópico aborda-se em específico o homeschooling no Brasil e as construções feitas por meio do RE 888.815/RS, após essa análise comparação a composição do mínimo existencial com este instituto educacional. Após estas reflexões por meio da dogmática hermenêutica, concluiu-se que atualmente não é possível a utilização do homeschooling por ele não permitir a consolidação do Direito/Dever de solidariedade e responsabilidade educacional pertencente aos pais e ao Estado. Assim, o patamar atual, de desregulamentação, não garante a consolidação e promoção do Direito Fundamental à Educação, se compreendida da forma como exposta. Por fim, a contribuição desse trabalho é de fomentar o debate e demonstrar as lacunas que devem ser preenchidas para que o homeschooling possa ser reconhecida como uma modalidade educacional.

\section{Referências}

ALEXY, Robert. Teoria dos direitos fundamentais. 2. ed. São Paulo: Malheiros, 2014.

BARBOZA, Estefânia Maria de Queiroz; KNIHS, Karla Kariny. O direito à educação domiciliar e os novos desafios ao Supremo Tribunal Federal: Recurso Extraordinário 888.815/RS, lacuna legislativa e direito comparado. Constituição, Economia e Desenvolvimento: Revista da ABDCONST. Curitiba, v. 9, n. 17, p. 399-430, jul./dez. 2017.

BARCELLOS, Ana Paula de. A eficácia jurídica dos princípios constitucionais: o princípio da dignidade da pessoa humana. 3. ed. Rio de Janeiro: Renovar, 2011.

BITTENCOURT NETO, Eurico. O direito ao minimo para uma existência digna. Porto Alegre: Livraria do Advogado, 2010.

BRASIL. Câmara dos Deputados. Projeto de Lei 2401/2019. Disponível em: $<$ https:/ /www.camara.leg.br/proposicoesWeb/fichadetramitacao?idProposicao $=2198615>$. Acesso em: 17 jan. 2020. 
BRASIL. Ministério da Educação. Censo Escolar 2017. Notas Estatísticas. Brasília. 2018.

Disponível em:

<http://download.inep.gov.br/educacao_basica/censo_escolar/notas_estatisticas/2018/notas_e statisticas_Censo_Escolar_2017.pdf>. Acesso em 16 jan. 2020.

BRASIL. Supremo Tribunal Federal Notícias. STF nega recurso que pedia reconhecimento de direito a ensino domiciliar. 12/09/2018. Disponível em: <

http://www.stf.jus.br/portal/cms/verNoticiaDetalhe.asp?idConteudo=389496>. Acesso em: 17 jan. 2020.

BRASIL. Supremo Tribunal Federal. Recurso Extraordinário n.888.815/RS. Plenário, Min. Rel. Roberto Barroso, julgado em 12/09/2018.

CAMBI, Eduardo; ZANINELLI, Giovana. Direito fundamental à educação, exclusão social e cidadania. Revista de Direito Privado, v. 59/2014, p. 29-54, jul./set. 2014.

CLÈVE, Clèmerson Merlin; FREIRE, Alexandre Reis Siqueira. Algumas notas sobre colisão de direitos fundamentais. In: CUNHA, Sérgio Sérvulo da; GRAU, Eros Roberto (orgs.). Estudos de Direito Constitucional em homenagem a José Afonso da Silva. São Paulo: Malheiros, 2003.

DWORKIN, Ronald. Levando os direitos a sério. 3. ed. São Paulo: Martins Fontes, 2010.

FREIRE, Paulo. Pedagogia do oprimido. Rio de Janeiro: Paz e Terra, 1977.

HACHEM, Daniel Wunder. A utilização do mínimo existencial como critério de exigibilidade judicial dos direitos fundamentais econômicos e sociais: reflexões críticas. Revista do Direito, Santa Cruz do Sul, n. 40, p. 90-141, ago./out. 2013.

HACHEM, Daniel Wunder. Princípio constitucional da supremacia do interesse público. Belo Horizonte: Fórum, 2011.

HACHEM, Daniel Wunder. Tutela administrativa efetiva dos direitos fundamentais sociais: Por uma implementação espontânea, integral e igualitária. Tese (Doutorado) Programa de Pós-Graduação em Direito, Setor de Ciências Jurídicas, Universidade Federal do Paraná. Orientador: Prof. Dr. Titular Romeu Felipe Bacellar Filho. Curitiba, 2014.

HONÓRIO, Cláudia. Olhares sobre o mínimo existencial em julgados brasileiros. 2009. 306 f. Dissertação (Mestrado em Direito) Programa de Pós-Graduação em Direito, Universidade Federal do Paraná, Curitiba, 2009.

KRELL, Andreas J. Direitos sociais e controle judicial no Brasil e na Alemanha. Os (des)caminhos de um Direito Constitucional "Comparado". Porto Alegre: Sergio Antonio Fabris Editor, 2002.

MALISKA, Marcos Augusto. Fundamentos da Constituição. Abertura, cooperação, integração. Curitiba: Juruá, 2013.

NOVAIS, Jorge Reis. Direitos sociais: teoria jurídica dos direitos sociais enquanto direitos fundamentais. Coimbra: Coimbra Editora, 2010. 
PIAGET, Jean. To understand is to invent: the future of education. Nova Iorque: The Viking Press, 1974. p. 54. Disponível em: < https://unesdoc.unesco.org/ark:/48223/pf0000006133>. Acesso em: 16 jan. 2020.

RIO GRANDE DO SUL. Tribunal de Justiça do Rio Grande do Sul. Apelação Cível n.70052218047. 8 a Câmara Cível; Des. Rel. Ricardo Moreira Lins Pastl; julgado em 16/05/2013.

SANTOS, Inalda Maria dos. A Reforma do Estado e a política de descentralização da educação no contexto na década de 1990. Dialogia, São Paulo, n. 29, p. 125-138, mai./ago. 2018.

SARLET, Ingo Wolfgang. A eficácia dos Direitos Fundamentais. 12. ed. Porto Alegre: Livraria do Advogado Editora, 2015.

SARLET, Ingo Wolfgang. Dignidade da pessoa bumana e direitos fundamentais na Constituição Federal de 1988. 9. ed. Porto Alegre: Livraria do Advogado, 2012.

SARLET, Ingo Wolfgang. Direitos Fundamentais orçamento e "reserva do possível". 2. ed. rev. e ampl. 2. tir- Porto Alegre: Livraria do Advogado Editora, 2013.p.20.

SARLET, Ingo Wolfgang; FIGUEIREDO, Mariana Filchtiner. Reserva do possível, mínimo existencial e direito à saúde: algumas aproximações. In: SARLET, Ingo Wolfgang; TIMM, Luciano Benetti (coords.). Direitos fundamentais: orçamento e "reserva do possivel". 2. ed. Porto Alegre: Livraria do Advogado, 2010.

SARLET, Ingo Wolfgang; ZOCKUN, Carolina Zancaner. Notas sobre o mínimo existencial e sua interpretação pelo STF no âmbito do controle judicial das políticas públicas com base nos direitos sociais. Revista de Investigações Constitucionais. Curitiba, v. 3, n. 2, p. 115-141, maio/ago. 2016.

SCHIER, Paulo Ricardo; SCHIER, Adriana da Costa Ricardo. O Serviço Público Adequado e a Cláusula de Proibição de Retrocesso Social. Revista de Direito da Administração Pública. Universidade Federal Fluminense, a. 2, v. 2, n. 1, jan/jun 2016.

SILVA, José Afonso da. Comentário contextual à Constituição. São Paulo: Malheiros, 2005.

SILVA, José Afonso da. Curso de Direito Constitucional Positivo. 18. ed. São Paulo: Malheiros: 2000.

SILVA, Virgílio Afonso da. Princípios e regras: mitos e equívocos acerca de uma distinção. Revista Latino-Americana de Estudos Constitucionais, n. 1, Belo Horizonte: Del Rey, p. 607-629, jan./jun. 2003.

TORRES, Ricardo Lobo. O direito ao minimo existencial. Rio de Janeiro: Renovar, 2009.

VICTOR, Rodrigo Albuquerque de. Judicialização de políticas públicas para a educação infantil. São Paulo, SP: Editora Saraiva, 2011.

XAVIER, Carlos. Educação domiciliar no Brasil: aspectos filosóficos, políticos e jurídicos. Rio de Janeiro: Instituto Angelicum, 2019. 
Recebido em: 28 jan. 2020 / Aprovado em: 27 fev. 2020

\section{Cite como (ABNT NBR 6023:2018)}

SOUZA, Maristela Denise Marques de; FERRAZ, Miriam Olivia Knopik; FERNEDA, Ariê Scherreier. O direito humano à educação e o homeschooling no Brasil: análise constitucional da compatibilidade com o mínimo existencial à educação. Dialogia, São Paulo, n. 34, p. 8-21, jan./abr. 2020. Disponível em: https://doi.org/10.5585/Dialogia.N34.16459.

\footnotetext{
i Capítulo II "Dos Direitos Sociais” pertencente ao Título "Dos Direitos e Garantias Fundamentais".

ii "o acesso ao ensino obrigatório e gratuito é direito público subjetivo"

iii Sobre esta teoria ver: SILVA, 2003 e HACHEM, 2011. p. 136-144.

iv Nos termos do art. 205 da Constituição da República Federativa do Brasil.

v Nos termos do art. 55 do Estatuto da Criança e do Adolescente.

vi Votos: Ministro Roberto Barroso (relator): provimento; Ministro Alexandre de Moraes (relator do acórdão): desprovimento; Ministro Edson Fachin: parcial provimento; Ministra Rosa Weber: desprovimento; Ministro Luiz Fux: desprovimento; Ministro Ricardo Lewandowski: desprovimento; Ministro Gilmar Mendes: desprovimento; Ministro Marco Aurélio: desprovimento; Ministro Dias Toffoli: desprovimento; Ministra Cármem Lúcia: desprovimento.

vii Há, no entanto, Projetos de Lei que preveem a regulamentação do ensino domiciliar, quais sejam: PL $3179 / 2012$ e 2401/2019, os quais alteram o Estatuto da Criança e do Adolescente e a Lei de Diretrizes e Bases da Educação Nacional.

viii Sobre a descentralização da educação consulte: SANTOS, 2018, p. 125-138.
} 